\title{
Biokinetics and dosimetry of commonly used radiopharmaceuticals in diagnostic nuclear medicine - a review
}

\author{
Uta Eberlein • Jörn Hendrik Bröer • \\ Charlot Vandevoorde • Paula Santos • Manuel Bardiès • \\ Klaus Bacher • Dietmar Nosske • Michael Lassmann
}

Received: 10 June 2011 / Accepted: 2 August 2011 / Published online: 30 August 2011

(C) The Author(s) 2011. This article is published with open access at Springerlink.com

\begin{abstract}
Purpose The impact on patients' health of radiopharmaceuticals in nuclear medicine diagnostics has not until now been evaluated systematically in a European context. Therefore, as part of the EU-funded Project PEDDOSE. NET (www.peddose.net), we review and summarize the current knowledge on biokinetics and dosimetry of commonly used diagnostic radiopharmaceuticals.

Methods A detailed literature search on published biokinetic and dosimetric data was performed mostly via PubMed (www.ncbi.nlm.nih.gov/pubmed). In principle the criteria for inclusion of data followed the EANM Dosimetry Committee guidance document on good clinical reporting. Results Data on dosimetry and biokinetics can be difficult to find, are scattered in various journals and, especially in
\end{abstract}

Electronic supplementary material The online version of this article (doi:10.1007/s00259-011-1904-z) contains supplementary material, which is available to authorized users.

\section{U. Eberlein $(\square) \cdot$ M. Lassmann}

Department of Nuclear Medicine, University of Würzburg,

Oberdürrbacher Str. 6,

97080 Würzburg, Germany

e-mail: eberlein_u@klinik.uni-wuerzburg.de

\section{J. H. Bröer · D. Nosske}

Department of Radiation Protection and Health,

Federal Office for Radiation Protection,

Oberschleißheim, Germany

C. Vandevoorde $\cdot \mathrm{K}$. Bacher

Department of Basic Medical Sciences,

Division of Medical Physics, Ghent University,

Ghent, Belgium

P. Santos $\cdot$ M. Bardiès

INSERM UMR892,

Nantes, France paediatric nuclear medicine, are very scarce. The data collection and calculation methods vary with respect to the time-points, bladder voiding, dose assessment after the last data point and the way the effective dose was calculated. In many studies the number of subjects included for obtaining biokinetic and dosimetry data was fewer than ten, and some of the biokinetic data were acquired more than 20 years ago.

Conclusion It would be of interest to generate new data on biokinetics and dosimetry in diagnostic nuclear medicine using state-of-the-art equipment and more uniform dosimetry protocols. For easier public access to dosimetry data for diagnostic radiopharmaceuticals, a database containing these data should be created and maintained.

Keywords Dosimetry · Biokinetics · Diagnostic radiopharmaceuticals Effective dose

\section{Introduction}

Diagnostic procedures imply the administration of activity levels that do not lead to the appearance of radiation deterministic effects; therefore only stochastic risks have to be considered. This means that the stochastic risk associated with exposure to ionizing radiation cannot be assessed for an individual patient. However, the concept of risk associated with a diagnostic procedure is valid for a population of patients, and requires, as a prerequisite, the determination of the absorbed dose, i.e. the energy absorbed per unit mass (in grays) in all irradiated tissues or organs of interest.

In a diagnostic context, determination of absorbed doses (i.e. a dosimetric study) is also required before the introduction of a new radiopharmaceutical to the market in order to obtain marketing authorization from the relevant 
agency such as the European Medicines Agency (EMA) or the Food and Drug Administration (FDA). This also helps to determine the range of activity to inject for a given procedure. In addition, "good clinical practice" implies injecting the minimum activity compatible with the diagnostic purpose, and assessing the radiation exposure delivered by that amount of activity.

Hence, the purpose of dosimetry within the context of radiation risk assessment for diagnostic nuclear medicine procedures is twofold:

1. Determination of reference levels of irradiation for every new radiopharmaceutical.

For a new radiopharmaceutical, the determination of reference levels of irradiation and consequently of the risks associated with the administration first requires an accurate determination of the biokinetics of the tracer. This step is usually carried out via quantitative imaging, blood sampling or excreta measurements in a restricted number of patients (or healthy volunteers). Some data are also derived from preclinical experiments in animals. Pharmacokinetics modelling is also often used at this stage. Then, based on the tracer distribution in space and time, radiation dose is calculated using phantoms, i.e. computational models that mimic organ geometry, organ-to-organ distances, and body composition of patients.

2. Provision of absorbed dose estimates for radiopharmaceuticals in routine use.

The provision of absorbed dose estimates for radiopharmaceuticals in routine use is generally a simple task since it requires only a patient-specific determination of the administered activity (in megabecquerels), a task performed routinely in nuclear medicine departments prior to injection. Then, using precalculated tables (e.g. the ICRP reports [1-3]) that for a given radiopharmaceutical give the absorbed dose in organs or tissues for a reference model per injected activity (in megabecquerels), it is possible to derive an estimate of the absorbed dose delivered to a reference person. This step implicitly relies on the hypothesis that the kinetic model chosen to establish precalculated tables satisfactorily reflects the average kinetics of the radiopharmaceutical in subjects of interest.

Evaluation of the impact on patients' health of the administration of small amounts of radioactive substances, or of amounts that are not or are only infrequently repeated, as currently used in diagnostic imaging procedures, relies heavily on a precise and accurate determination of reference levels of irradiation, and it affects the quality of the data used further for routine diagnostic procedures. This impact, however, has not been addressed systematically in a European context. Data on biokinetics and dosimetry of these agents are reported in diverse and widespread sources and are sometimes difficult to access. Therefore, the European Commission addressed this issue in the framework of the FP 7 HEALTH-2009-1.2-6 project PEDDOSE. NET ("Dosimetry and Health Effects of Diagnostic Applications of Radiopharmaceuticals with particular emphasis on the use in children and adolescents"). One of the main objectives of this project is to summarize and evaluate the current knowledge on dosimetry and the corresponding dose-related risks when administering radiopharmaceuticals for diagnostic purposes in children and adults.

The aim of this review is to provide detailed data on biokinetics and dosimetry for diagnostic radiopharmaceuticals in children and adults, and it focuses on assessing how absorbed doses were derived.

\section{Material and methods}

Literature on the available biokinetics and dosimetry data was systematically reviewed, mostly using PubMed (www. ncbi.nlm.nih.gov/pubmed) and the secondary literature cited in the articles found. Primarily, we concentrated on radiopharmaceuticals commonly used in Europe.

The following inclusion criteria were used:

- Publications of official bodies such as the International Commission on Radiological Protection (ICRP) [1-3]

- Peer-reviewed journals

- Special conference proceedings containing detailed descriptions on methodologies in dosimetry

The literature was searched back to the publication date of ICRP 53 (1987) [1] if there were no other data available. In principle the following criteria for inclusion of data as defined by the EANM Dosimetry Committee guidance document on good clinical reporting [4] were used:

- The quantitative imaging method used: planar, SPECT(/CT) or PET(/CT), and potential corrections (e.g. attenuation and scatter correction). The fewer corrections the authors applied the higher was the likelihood of increased uncertainties in the assessment of residence times. ${ }^{1}$

- The availability of data on biokinetics, in particular detailed information on residence times and how they were derived. Providing residence times enables a potential recalculation and reassessment of the absorbed doses and hence the effective dose (ED) if needed.

- Organ masses can differ by more than a factor of 3 [6]. As a SPECT, PET, CT or MRT scan allow the

\footnotetext{
${ }^{1}$ The term "residence time" has been changed in MIRD Pamphlet No. 21 [5] to "time-integrated activity coefficient".
} 
measurement of organ volumes and therefore masses, several studies have assumed uniform distribution of activity and applied a first-order correction by multiplying the activity concentration by the phantom organ weight, resulting in normalized time-activity curves and residence times.

- Another aspect of importance is the time-points at which the measurements for determining the timeactivity curves were made. To obtain a reliable assessment of the area under the curve, a minimum of three data points is recommended (MIRD 16 [7]) and the time between the first and the last measurement should not be too short, otherwise the absorbed dose would be overestimated when using physical decay after the last data point.

- Information on bladder voiding intervals is also crucial because for some radiopharmaceuticals (e.g. ${ }^{18} \mathrm{~F}$-fluoride) the absorbed dose to the bladder depends very much on the voiding period and the first voiding after injection; therefore, the ED differs between datasets with different voiding intervals.

- Detailed information on the absorbed doses to the relevant organs and, if available, the way they were calculated (i.e. the computer code and the source of the S-values ${ }^{2}$ ) are essential, especially for a comparison of the results. Scaling the S-values with individual organ masses is useful for patient dosimetry in radionuclide therapy but deviates from the usual approach for the dosimetry of diagnostic procedures. Furthermore, calculation of ED is not based on individual patient data. Calculating ED according to ICRP is based on reference values for the human body and organs [9].

- The tissue-weighting factors for describing the radiation-related risk changed in 1991 with the publication of ICRP 60 [10]. In this work the ED was introduced. Prior to ICRP 60 the quantity "effective dose equivalent (EDE)" [11] was used. In 2007 the ICRP (ICRP 103 [9]) published a new set of tissueweighting factors and a new calculation method. Therefore, when comparing EDs one has to know which tissue weighting factors were used.

- The reliability of dosimetry data is highly dependent on the number of participants in a study. It is important to know the number of volunteers/patients who took part in a dosimetry study because this affects the variability in individual biokinetics.

In this review a summary of the most important findings is given. Details on the available data in the references sorted according to these criteria are given in the Electronic

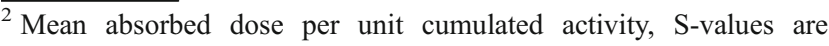
radionuclide-specific, and represent physical and geometrical factors [8]
}

supplementary material in Tables $1.1-1.4$ and $2.1-2.6$ for adults and in Tables 3.1-3.4 for children. If there were no data available, the corresponding radiopharmaceuticals are not listed in the table. In addition, the reference values for each radiopharmaceutical taken from the latest respective ICRP report [1-3] are also listed in order to compare these data with the ED or, if not available, EDE values in the cited references.

\section{Results}

The investigated PET and non-PET radiopharmaceuticals with and without marketing authorization are displayed in Tables 1 and 2, respectively.

In the following sections the most important findings of our literature search are summarized. Further details not provided in the text are given in the corresponding tables in the Electronic supplementary material.

\section{PET radiopharmaceuticals}

As a whole-body scan with a PET scanner can take $30 \mathrm{~min}$ or more (especially with older PET systems) and the uptake of many PET radiopharmaceuticals occurs within $10 \mathrm{~min}$ of injection, many studies involving the detailed measurement of time-activity curves are limited to scanning only one organ per subject. Subsequently, the results of many singleorgan measurements are merged into a "virtual" subject for a complete biokinetic model and calculation of absorbed doses. If the number of participants is large enough, individual variations should not be important, but the small size of many studies leads to organ data based on few subjects. In these cases the results have to be viewed with care, as ICRP 106 [3] mentions in the section "Uncertainties in absorbed dose estimates" that intersubject variability may introduce considerable variation in accumulated activity. A detailed analysis of uncertainties in internal dose calculations for radiopharmaceuticals has also been given by Stabin [12].

It is desirable that dosimetric publications include the individual residence times, because in combination with administered activities reanalysis of patient data is feasible if new or different dosimetry and calculation methods should become available [4]. Unfortunately, most studies omit the individual data and state only the mean values and standard deviations, which can only provide a rough estimate of intersubject variance.

\section{${ }^{11}$ C-Acetate}

Acetate is used in the assessment of myocardial oxidative metabolism [13] and in renal, pancreatic and nasopharyngeal 
Table 1 PET radiopharmaceuticals considered in this review indicating their European marketing authorization status. No product names are given for radiopharmaceuticals with more than one trademark

\begin{tabular}{|c|c|c|c|}
\hline \multirow[t]{2}{*}{ Radiopharmaceutical } & \multirow[t]{2}{*}{ Authorized } & \multicolumn{2}{|l|}{ Not authorized } \\
\hline & & Well-established & Not well-established \\
\hline \multicolumn{4}{|l|}{${ }^{18} \mathrm{~F}$} \\
\hline Florbetaben (formerly BAY94) & & & $\mathrm{x}$ \\
\hline FET & & $\mathrm{x}$ & \\
\hline Choline (IASOcholine ${ }^{\mathbb{R}}$ ) & $\mathrm{x}^{\mathrm{a}}$ & & \\
\hline DOPA & $\mathrm{x}$ & & \\
\hline FDG & $\mathrm{x}$ & & \\
\hline Fluoride (IASOflu ${ }^{\mathbb{R}}$ ) & $\mathrm{x}$ & & \\
\hline FLT & & & $\mathrm{x}$ \\
\hline MISO & & & $\mathrm{x}$ \\
\hline \multicolumn{4}{|l|}{${ }^{11} \mathrm{C}$} \\
\hline Acetate & & $\mathrm{x}$ & \\
\hline Choline & & & $\mathrm{x}$ \\
\hline Methionine & & $\mathrm{x}$ & \\
\hline PIB & & & $\mathrm{x}$ \\
\hline PK11195 & & & $\mathrm{x}$ \\
\hline \multicolumn{4}{|l|}{${ }^{68} \mathrm{Ga}$} \\
\hline DOTANOC & & $\mathrm{x}$ & \\
\hline DOTATATE & & $\mathrm{x}$ & \\
\hline DOTATOC & & $\mathrm{x}$ & \\
\hline \multicolumn{4}{|l|}{${ }^{82} \mathrm{Rb}$} \\
\hline Generator (CardioGen-82 $\left.{ }^{\circledR}\right)$ & & $x^{b}$ & \\
\hline
\end{tabular}

${ }^{a}$ Marketing authorization currently only in France.

${ }^{\mathrm{b}}$ Approved by the US Food and Drug Administration (FDA)

disease [3]. More recently ${ }^{11} \mathrm{C}$-acetate has become an important tracer for imaging prostate cancer $[14,15]$. The only human study on quantitative whole-body imaging is that by Seltzer et al. [15] which included six healthy male volunteers. In this detailed study the individual residence times in all the volunteers were determined for the important organs, and the organ doses were calculated for the mean values using MIRDOSE3.1 [16]. The data were compared with data published by the Oak Ridge Institute for Science and Education (ORISE) in 1995 (no detailed citation information available) which were based on a simple threecompartment model in which all activity not measured in the blood or excreted via the breath was assumed to reside in the heart [15]. The experiments were performed in dogs; activity was measured only in the blood and expired air [17].

The latest ICRP report (ICRP 106 [3]) relies on tabulated blood flow data for most human tissues by Leggett and Williams [18]. The study by Seltzer et al. [15], however, was not used in ICRP 106 [3].

\section{${ }^{11}$ C-Choline}

Choline is used for the imaging of prostate and brain tumours. Roivainen et al. [19] showed that it is rapidly metabolized and cleared from the blood. Tolvanen et al.
[20] performed a complete dosimetric study. They compared data from normal and tumour-bearing rats and from six patients. The rat-derived and human-derived absorbed organ doses differed by up to a factor of approximately 6 , while the rat-derived and human-derived ED differed by a factor of approximately 1.5 .

\section{${ }^{11}$ C-Methionine}

Methionine is used in tumour diagnosis. There is only one study on whole-body PET [21] which included five volunteers and gives all relevant information for dosimetry. This study was also used as a basis for the biokinetic model in ICRP 106 . However, the ED calculated by ICRP is $60 \%$ higher than the one calculated by Deloar et al. [21].

\section{${ }^{18}$ F-Florbetaben (BAY94)}

Florbetaben is specific for beta-amyloid and is therefore used in the diagnosis of Alzheimer's disease. There is one published study [22] on dosimetry that included only three subjects and partially omitted biokinetic data. While the authors show time-activity curves for several organs, they do not give residence times.

\section{${ }^{18}$ F-Choline}

Just like ${ }^{11} \mathrm{C}$-choline, ${ }^{18} \mathrm{~F}$-choline is primarily used in the detection of prostate cancer and its metastases in bone. Since 2010 it has had marketing authorization only in France under the name IASOcholine ${ }^{\circledR}$; other European countries will follow soon [23]. Currently it is not known if the biokinetics of ${ }^{11} \mathrm{C}$ - and ${ }^{18} \mathrm{~F}$-labelled choline are different. According to Roivainen et al. [19], ${ }^{11} \mathrm{C}$-choline is rapidly metabolized into ${ }^{11} \mathrm{C}$-betaine while DeGrado et al. [24] have speculated that differences in blood clearance can be explained by metabolic trapping of ${ }^{18} \mathrm{~F}$-choline. DeGrado et al. [24] compared animal and human data. As they assumed instantaneous uptake and no biological clearance they probably overestimated the radiation dose. The authors did not provide biokinetic data for individual subjects. A correction for the male organ dose has been published as an erratum [24]. Nosske and Brix [25] developed a biokinetic model based on the available data for humans. They assumed equal biokinetics for ${ }^{11} \mathrm{C}$ - and ${ }^{18} \mathrm{~F}$-choline. Janzen et al. [26] provided extensive data on dosimetry; and in addition they explained their compartment model in detail.

Zankl et al. [27] were mainly interested in comparing the absorbed dose of locally absorbed electrons and electron-specific absorbed fraction values calculated using a Monte-Carlo method in a voxel-based computational phantom. Therefore, the biokinetic data for a 
Table 2 Non-PET radiopharmaceuticals considered in this review indicating their European marketing authorization status. No product names are given for radiopharmaceuticals with more than one trademark

\begin{tabular}{ll}
\hline Radiopharmaceutical $\quad$ Authorized & Not authorized \\
\cline { 2 - 2 } & Well-established Not well-established
\end{tabular}

\section{${ }^{99 \mathrm{~m}} \mathrm{Te}$}

Antigranulocyte $\left(\right.$ Scintimun $\left.^{\circledR}\right) \quad \mathrm{x}$

DMSA

DTPA

ECD (Neurolite $\left.{ }^{\circledR}\right)$

HMPAO (Ceretec $\left.{ }^{\mathrm{TM}}\right)$

MAA

MAG3

MDP (Medronate)

Pertechnetate

Sestamibi (MIBI)

Small colloids (Nanocoll ${ }^{\circledR}$ )

Technegas ${ }^{\mathrm{a}}$

Tetrofosmin (Myoview ${ }^{\mathrm{TM}}$ )

${ }^{123} \mathrm{I}$

Ioflupane, FP-CIT (DaTSCANTM)

Iodide

MIBG

$\mathrm{OIH}$

${ }^{111}$ In

Antimyosin

DOTA-lanreotide

DOTATATE

DOTATOC

DTPAOC (Octreoscan $\left.{ }^{\mathrm{TM}}\right)$

Ibitrumomab (Zevalin $\left.{ }^{\circledR}\right)$

${ }^{201} \mathrm{Tl}$

Chloride

${ }^{67} \mathbf{G a}$

Citrate

${ }^{\mathrm{a}}$ Technegas is not marketed as radiopharmaceutical; it is licensed as a medical device.

single patient were sufficient for the purposes of their study, and they did not give any details about the acquisition of the data.

\section{${ }^{18}$ F-DOPA}

DOPA is an amino acid analogue which is marketed under the name of IASOdopa ${ }^{\circledR}$ in Austria, Germany and France. It is used in the diagnosis of several neurological and oncological diseases. The organ doses published in the SPC (Summary of Product Characteristics) [28] were taken from addendum 4 to ICRP 53 [29], which has been replaced by ICRP 106 [3]. No pretreatment with carbidopa was assumed in the ICRP 106 report and for the dosimetric data given in the SPC. Different biokinetics after this pretreatment have been reported, especially for the brain and bladder [30]. All the studies mentioned are included in ICRP 106; no newer literature is available.

\section{${ }^{18} F-F D G$}

The uptake of FDG is dependent on glucose metabolism and can be used in the detection of fast-growing cancer cells and inflammation. There are many studies that have included adult subjects, but in most either no whole-body scans were performed [31-36] or time-activity curves were fitted to the sum of two exponential functions to three data points only $[37,38]$. In two studies [33, 34] the experiments were repeated in the same subjects with small intrasubject variability.

Dowd et al. [32] measured urine activity only and developed a dynamic bladder model. Deloar et al. [37] used MRI to determine organ masses of their subjects and PET for activity distribution. Using these data they calculated residence times and absorbed doses utilizing the MIRD phantom, the Japanese reference man and Svalues scaled with the individual organ masses. A dynamic bladder model was not used and they did not provide individual data. This study was used in ICRP 106. In another study by Deloar et al. [38] the authors compared thermoluminescent dosimetry with whole-body PET-based dosimetry and found good agreement. They did not give individual patient data. While both studies by Deloar et al. [37, 38] give an identical ED, they were performed in different subjects and the organ doses vary slightly. The authors of MIRD Dose Estimate Report No. 19 [35] merged the data from four studies in which the biokinetic data for specific organs were determined. This study was used in ICRP 106.

$\mathrm{Wu}$ et al. [36] were interested in developing an improved bladder model and therefore imaged only the bladder. They reported absorbed doses to the bladder wall in relation to initial bladder volume and first urine voiding time and individual biokinetic data. Koukouraki et al. [39] studied the pretherapeutic use of FDG and gave the rate constants for a local diagnostic three-compartment model (a blood compartment and two tissue compartments). Khamwan et al. [40] imaged patients in a Thai hospital and developed a dosimetry for Thais. Due to missing biokinetic data and some omitted imaging details, it is difficult to evaluate the results of their study. They used tissue weighting factors from ICRP 103 [9] and the S-values of the MIRD phantom (70 kg reference man) scaled with the subjects' organ masses.

\section{${ }^{18}$ F-FET}

FET is an amino acid used in imaging lymphomas. Pauleit et al. [41] determined the biokinetics and performed a 
dosimetric assessment based on blood and urine samples and two whole-body scans. As they did not report details for the determination of the time-activity curves, the results cannot be heavily relied upon.

\section{${ }^{18}$ F-Fluoride}

Sodium fluoride is a bone-seeking pharmaceutical and is therefore used for bone scanning. In 1978 Charkes et al. [42] reported the rate constants for a whole-body fivecompartment model, which was used in ICRP 53. Since then further research has only been performed using a diagnostic local three-compartment model first used by Hawkins et al. [43]. The studies working with this model show a wide variation in bone uptake by a factor of up to 10 [44] depending on the location of the bone (usually vertebrae or humerus), hydration and the diseases of the subjects. Fluoride uptake into bone is around $50 \%$ in healthy subjects [1], so diseases affecting the whole skeletal system such as osteoporosis might significantly affect dosimetry.

In February 2011 fluoride was approved by the FDA, but the dosimetric data have not been updated and in the official FDA information EDE is still given [45]. In Europe, fluoride is now also available as IASOflu ${ }^{\circledR}$ [46]. In France it was approved as early as 2008. In the French SPC there is no recommendation given for the activity dosage in paediatric nuclear medicine [47].

\section{${ }^{18} \mathrm{~F}-\mathrm{MISO}$}

${ }^{18} \mathrm{~F}$-MISO is used in imaging hypoxia. Graham et al. [48] pooled the organ data obtained from 60 patients with scans differing in field of view and scanning time. They randomly chose a residence time from the pool for each measured source organ, used them to calculate the absorbed doses with S-values from MIRDOSE2 [16], and repeated this 1,000 times using a Monte-Carlo simulation. The resulting median values and $25 \%$ and $75 \%$ percentiles are presented in a table.

${ }^{68} \mathrm{Ga}$

All ${ }^{68} \mathrm{Ga}$-labelled radiopharmaceuticals mentioned here are peptide analogues that bind to somatostatin receptors, which are often overexpressed in neuroendocrine tumours. Despite its widespread use and ease of distribution $\left({ }^{68} \mathrm{Ga}\right.$ is eluted from a ${ }^{68} \mathrm{Ge} /{ }^{68} \mathrm{Ga}$ radionuclide generator), the literature on ${ }^{68} \mathrm{Ga}$ is sparse. For ${ }^{68} \mathrm{Ga}$-DOTANOC, a single but well done study is available [49]. Despite an intensive search, no publications dealing with dosimetry for ${ }^{68} \mathrm{Ga}$-DOTATATE were found. There are data only for ${ }^{111}$ In-DOTATATE and ${ }^{177} \mathrm{Lu}$-DOTATATE used in therapy [50]. The pretherapeutic use of ${ }^{68} \mathrm{Ga}$-DOTATOC has been studied [39], and Hartmann et al. [51] performed a complete dosimetric study of ${ }^{68} \mathrm{Ga}$ DOTATOC, although the significance of the difference between the reported male and female ED values seems doubtful due to the small number of subjects.

\section{${ }^{82} \mathrm{Rb}$ Generator}

${ }^{82} \mathrm{Rb}$ is commercially available as CardioGen- $82^{\circledR}$ (a ${ }^{82} \mathrm{Sr} /{ }^{82} \mathrm{Rb}$ generator) and is used in cardiac imaging; it is approved by the FDA. The absorbed organ doses in the SPC [52] are based on studies in rats [53] and only two humans [54]. The ICRP calculations are based on a theoretical model of blood flow and represent "worst case" conditions. Stabin [55] has proposed a revision to the radiation dosimetry of ${ }^{82} \mathrm{Rb}$. He compared the blood-flow model of the ICRP [1] with a blood-flow model proposed by Leggett and Williams [18] and with the data from the two humans [54]. He analysed the biokinetic data using OLINDA/EXM dose calculation software [56], and concluded that the model of Leggett and Williams is most appropriate for general use. The latter model provided an ED that was smaller than the ICRP's "worst case condition" by a factor of 2. Senthamizhchelvan et al. studied the biodistribution in ten healthy volunteers at rest [57] and under pharmacological stress [58]. The studies were methodologically correct and well accomplished and provided new results, with the exception of the improper use of ICRP 103 weighting factors (see Discussion). However, in both studies [57, 58], ED values were also calculated using the ICRP 60 weighting factors. The calculated EDs are comparable to those obtained by Stabin [55] using the data of Ryan et al. and Leggett and Williams. However, the ED value calculated using the data of Leggett and Williams is $50 \%$ higher than the value calculated by Senthamizhchelvan et al., while the value calculated using the data of Ryan et al. is $30 \%$ lower.

\section{Other radiopharmaceuticals}

\section{${ }^{99 m}$ Tc-Antigranulocyte}

${ }^{99 \mathrm{~m}} \mathrm{Tc}$-antigranulocyte is a monoclonal antibody (BW 250/ 183) produced in murine cells and used in determining the location of inflammation/infection in peripheral bone in adults with suspected osteomyelitis [59]. It was approved by the EMA in 2010 and is marketed under the name Scintimun ${ }^{\circledR}$. Published data on biokinetics are available but without residence times for calculating absorbed doses [6062]. The biokinetic study of Buchmann et al. [62] evaluated the suitability of ${ }^{99 \mathrm{~m}} \mathrm{Tc}$-anti-CD66 monoclonal antibody BW 250/183 for myeloablative radioimmunotherapy.

No published dosimetry data were found in peer-reviewed journals for the monoclonal antibody BW 250/183. In the core 
SPC of IBA Molecular [63] and the core SPC of the EMA [59] data on dosimetry have been included. However, in the SPC of IBA Molecular only the organ doses and the EDE have been given. These data contain no detailed description of the origin of the biokinetic and dosimetric data. The same applies to the data in the core SPC of the EMA. ${ }^{3}$ In this SPC the organ doses were calculated for the reference man and the reference woman separately and then the ED was calculated using the ICRP 103 [9] tissue weighting factors. As noted in the discussion, ICRP 103 should not yet be used for describing the risk of medical procedures in nuclear medicine.

${ }^{99 m} T c-M A A$

Most commonly, MAA is used in lung perfusion imaging for the diagnosis or exclusion of pulmonary emboli. The biokinetic model adopted by ICRP 53 is the same as that used for iodine-labelled MAA [1], except for the excretion model which is replaced by the model for ${ }^{99 \mathrm{~m}}$ Tc-pertechnetate when a blocking agent has been given. The latest data on quantitative imaging were published in 1983 by Malone et al. [64]. According to ICRP 53 [1], the quantitative data on the metabolism of iodine- and technetium-labelled MAA in the literature show discrepancies.

\section{${ }^{99 m} T c-$ Pertechnetate}

Pertechnetate is used in imaging the thyroid and salivary glands, and for the diagnosis of Meckel's diverticulum. Biokinetic data are available in ICRP 53 [1], and no newer data have been published. The biokinetic model of ICRP 53 relies on data published in 1965, 1966 and 1969, and on data published in the MIRD Dose Estimate Report No. 8 in 1976 [65], the latter relying on a compartment model proposed by Hays and Berman [66]. Smith et al. [67] calculated organ doses and ED for the well-established MIRD system of mathematical anthropomorphic phantoms and a family of realistic voxel phantoms using the biokinetic data published in ICRP 53 [1], and compared the results.

\section{${ }^{99 m}$ Tc-Sestamibi (MIBI)}

Sestamibi is mainly used in imaging the myocardium. The latest data found were publications that were used for the biokinetic model in ICRP 80 by Wackers et al. [68] and Leide et al. [69]. In both studies rest and stress tests were

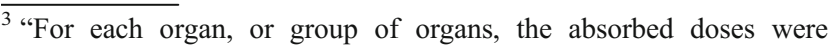
calculated using the methodology developed by MIRD (Medical Internal Radiation Dose)" [59]
}

conducted. There are significant differences in MIBI uptake in several organs between rest and stress studies; these also differ considerably between individual subjects [69].

\section{${ }^{99 m} T c-T e c h n e g a s$}

Technegas is used in lung ventilation scintigraphy to diagnose pulmonary embolism. It is an aerosol of ultrafine ${ }^{99 \mathrm{~m}} \mathrm{Tc}$ labelled carbon particles with a particle size around $50 \mathrm{~nm}$ [70]. A summary of the biokinetics can be found in ICRP 80 [2], according to which a biokinetic model was developed. None of the references in ICRP 80 provide organ doses for organs other than the lung. The organ dose for the lung is reported as $4.5 \mathrm{mSv} / 37 \mathrm{MBq}$ [71]. This organ dose relies on data published in the "Handbook of radiation doses in nuclear medicine and diagnostic X-ray" [72] to which we were not allowed access, and hence could not assess how this dose was calculated.

\section{${ }^{99 m}$ Tc-Tetrofosmin}

Tetrofosmin, marketed as Myoview ${ }^{\mathrm{TM}}$, is used in myocardial perfusion imaging and in imaging of the female breast. Biokinetic and dosimetric data are published in the latest ICRP report (ICRP 106) [3]. However, due to a printing error, the values in the ICRP 106 table for the resting subject and the subject under stress are identical. The data in both tables belong to the stress data (personal communication with a member of the ICRP task group). Unfortunately, an erratum has never been published by ICRP. Although the biokinetic data are the same in ICRP 80 and ICRP 106, the absorbed doses to the organs, and hence the ED, are slightly different in the stress studies (probably in the rest study too, but these data are not available). This is due to the fact that the ICRP has changed the phantoms and the source of the S-values used for calculating the doses. For ICRP 53 and ICRP 80 [1, 2], a $70-\mathrm{kg}$ adult male phantom was considered that was described in MIRD Pamphlet No. 5 Revised [73], and which was based on the ICRP 23 [74] reference man. The corresponding S-values used for absorbed dose calculations were taken from MIRD Pamphlet No. 11 [8]. For children the phantoms considered were those developed by Cristy [75].

For ICRP 106 [3], the phantoms considered were those developed by Cristy and Eckerman [76] for both adult male and children. The whole-body mass of the adult phantom of Cristy and Eckerman changed slightly to $73.7 \mathrm{~kg}$. For absorbed dose calculations the published S-values of Stabin and Siegel [77] were used.

The biokinetics are quite similar to those of sestamibi. However, tetrofosmin is cleared more rapidly from the liver and the absolute uptake in the heart is lower. The biokinetic 
data in ICRP 80 and ICRP 106 are based on publications by Smith et al. [78] and Higley et al. [79]. Both studies were conducted in the same hospitals (multicentre study with two hospitals) and the same number of patients. It is not clear if the patient groups were identical because the injected activity differed between the studies. However, the calculated EDs are the same in both publications. The dosimetric data provided by GE Healthcare in the core SPC [80] are human data; the source of the data, however, is not referenced.

\section{${ }^{201}$ Tl-Chloride}

${ }^{201} \mathrm{Tl}$ is used in myocardial perfusion imaging. There are discrepancies in the reported amounts of testicular uptake of ${ }^{201} \mathrm{Tl}$-chloride [3]: uptake values in the range $0.15-1.1 \%$ (percentage uptake at $24 \mathrm{~h}$ ) have been reported [81]. In a revised dosimetry study, Thomas et al. [81] performed quantitative imaging for the testes only, shielded from the body background. They combined these data with biokinetic data from older publications. With these datasets for the testes the absorbed dose per administered activity calculated in this study is less than $50 \%$ of the previously accepted value. These data have also been included in the ICRP 106 [3] data in combination with the data of Krahwinkel et al. [82]. Therefore, a testicular uptake of $0.3 \%$ has generally been adopted instead of $0.8 \%$ (ICRP 53 [1] and ICRP 80 [2]). That is the reason why the recalculation of the ED performed in ICRP 106 shows a substantial decrease as compared to ICRP 80 (0.14 mSv/MBq vs. $0.22 \mathrm{mSv} / \mathrm{MBq})$.

\section{${ }^{123}$ I-Iodide}

Sodium Iodide is used in the evaluation of thyroid function and/or morphology. In 2003 a refinement of the ICRP 53 biokinetic model was published by Johansson et al. [83]. In this compartment model the uptakes in the stomach wall and the salivary glands were included resulting in a slight change in the ED compared to the ED reported in ICRP 80 [2].

\section{${ }^{123}$ I-Ioflupane $\left({ }^{123}\right.$ I-FP-CIT)}

Ioflupane is a cocaine analogue used in imaging dopamine transporters (DaT). GE Healthcare holds a marketing authorization under the name DaTSCAN'TM. In 1998 a phase I biodistribution and dosimetry study was published by Booij et al. [84]. The residence times for several source organs were calculated separately for each subject fitting a multicompartment model to the time-activity curves for these organs. Furthermore, the absorbed doses to the organs were calculated for each subject independently and averaged. An erratum has been published containing a correction of the residence time for the gallbladder content; however, this does not affect the value of ED [84]. The manufacturer-provided data published in the SPC [85] include absorbed doses for the target organs and the ED, but there is no reference as to how these data were derived. Comparing the absorbed doses and the ED given in the SPC with the data in the paper by Booij et al. [84] shows that these data were used for the SPC.

${ }^{111} I n$

Most of the radiopharmaceuticals (except Zevalin) presented in this section are somatostatin derivatives (see the section about ${ }^{68} \mathrm{Ga}$ ). There is one study on ${ }^{111}$ In-DOTA-lanreotide with complete dosimetric data [86] and one on therapy with ${ }^{90} \mathrm{Y}$ [87] comparing DOTA-lanreotide and DOTATOC. For ${ }^{111}$ In-DOTATATE information is scarce. A single report [88] presents data for blood clearance and calculated absorbed organ doses for ${ }^{90} \mathrm{Y}$ therapy. Two studies on ${ }^{111} \mathrm{In}$-DOTATOC are available, one with absorbed organ doses and partly omitted biokinetics [89] and the other with residence times determined with a compartment model [90].

${ }^{111}$ In-DTPAOC (also known as DTPA-octreotide or pentetreotide) is marketed as OctreoScan ${ }^{\mathrm{TM}}$. The reports by Bajc et al. [91] and Stabin et al. [92] contain all relevant data for dosimetry. Two other studies [93, 94] have considered only the pretherapeutic use of ${ }^{111}$ In-DTPAOC and estimated biokinetic data for ${ }^{90} \mathrm{Y}$-DOTATOC have been published.

Ibritumomab, licensed as Zevalin ${ }^{\circledR}$, is an antibody that is labelled with either ${ }^{111} \mathrm{In}$ or ${ }^{86} \mathrm{Y}$ for pretherapeutic imaging or ${ }^{90} \mathrm{Y}$ as a therapeutic agent against lymphomas. In the EU Zevalin has marketing authorization only for therapeutic use with ${ }^{90}$ Y. Two reports by Wiseman et al. $[95,96]$ present only estimated absorbed organ doses for therapy, while MIRD Dose Estimate Report No. 20 [6] provides complete biokinetic and dosimetric data for ${ }^{111}$ In-ibritumomab.

\section{${ }^{67} \mathrm{Ga}$-Citrate}

${ }^{67} \mathrm{Ga}$-citrate is used for localization of inflammatory lesions. The only available biokinetic and dosimetric data were published in the MIRD Dose Estimate Report No. 2 in 1973 [97]. These data were used for the biokinetic model in ICRP 53 [1].

Dosimetry data in paediatric nuclear medicine

In the following we present a summary of the few data available for paediatric applications in nuclear medicine diagnostics. Further details are given in the tables in the Electronic supplementary material.

In general ICRP uses the same biokinetic models for children as for adults and paediatric age-dependent math- 
ematical phantoms to calculate absorbed doses in children as there is a lack of specific knowledge. According to ICRP [1], it is assumed that this might lead to an overestimate of the absorbed dose because of shorter biological halflives in children than in adults; however, the measurements for ${ }^{99 \mathrm{~m}}$ Tc-DMSA and ${ }^{99 \mathrm{~m}}$ Tc-HMPAO in children show that the kinetics are not very different.

\section{${ }^{18} F-F D G$}

Only two publications actually present measured data for paediatric subjects. Ruotsalainen et al. [98] imaged the brain and bladder of newborns with serious neurological symptoms. The residence times of other organs were taken from the literature and scaled according to body and brain mass. Then the S-values of a newborn Cristy-Eckerman phantom [99] were used for calculation of absorbed doses. They found that only $4 \%$ to $7 \%$ of injected activity is excreted into the bladder while ICRP 106 assumes 24\%. Niven and Nahmias [100] examined very low birth weight newborns with suspected lung inflammation. As these patients were on average three times lighter than a fullterm newborn, they scaled the S-values of the newborn Cristy-Eckerman phantom with individual organ masses assuming target and source organ were identical. Due to large uncertainties, they were only able to calculate dosimetry for three cases based on assumptions.

\section{${ }^{18}$ F-Fluoride}

The review by Gelfand [101] includes (as do at least two other papers $[102,103])$ a table for absorbed doses of ${ }^{18} \mathrm{~F}$ fluoride in children that claims to be derived from ICRP 53, but the organ doses differ by up to $20 \%$. For example, the absorbed dose to the bladder wall of a 1-year-old child is $1.3 \mathrm{mSv} / \mathrm{MBq}$ according to Gelfand and $1.1 \mathrm{mSv} / \mathrm{MBq}$ according to ICRP 53.

\section{${ }^{99 m} T c-D M S A$}

Imaging was performed in 24 children aged from 5 weeks to 14.8 years (15 normal and 9 with renal pathology). The administered activities were scaled according to the EANM 1990 paediatric dosage card [104]. No obvious age dependencies in the biokinetics in children with normal renal function were found; only children younger than 1 year showed a reduced urinary excretion uptake [105]. Therefore the differences between adults and children with normal renal function are relatively small; the adult biokinetic data are a good approximation for all ages [105]. Absorbed dose calculations have also been reported by Smith et al. [106]. Their computer code used paediatric anthropomorphic phantoms representing children of ages 15, 10, 5 and 1 year weighing 55.6, 32.4, 18.6 and $9.9 \mathrm{~kg}$, respectively, and a newborn weighing $3.4 \mathrm{~kg}$. The children were matched to the closest phantom by age and weight. A second approach was also chosen: interpolation between the organ doses calculated with two adjacent phantoms for each child.

${ }^{99 m}$ Tc-HMPAO ( ${ }^{99 m}$ Tc-exametazime)

Vestergren et al. [107] evaluated the biokinetics of HMPAO in children. Since it is very difficult to study children, especially very young ones, only three whole-body scans were done (1, 7 and $24 \mathrm{~h}$ after injection). For the calculation of the absorbed doses in children the same biokinetic models as used in adults were used, and the age of each patient was rounded to the closest of the ages $0,1,5,10$ and 15 years and adult. For most organs no obvious age-dependent differences in the residence times were found. There were differences only in the brain and in the nonspecified organs [107].

${ }^{99 m} T c-M A G 3$

The dosimetry data in the publication on paediatric radiation dosimetry by Stabin et al. [108] rely on measured data from only four children at different ages (8 days, and 2.5, 5 and 14 years). The authors emphasized that these data were only preliminary and, therefore, no true agedependency has been identified.

${ }^{99 m} T c-M D P$

According to ICRP 53 (relying on data by Gelfand et al. [109]) the absorbed dose to the growing regions of children's bone is higher by a factor of 2-5 than assumed for the mean absorbed dose in adults and hence the mean absorbed dose in children using the adult biokinetics is not likely to be considerable underestimated.

\section{Discussion}

Compiling data on radiopharmaceutical dosimetry for diagnostic nuclear medicine inevitably leads to the question of up-to-date minimum standards for collecting reliable data for dosimetry. In principle, the steps described in MIRD Pamphlet No. 16 [7], ICRU 67 [110] and the EANM dosimetry guidance document on good dosimetry reporting [4] should be considered. Stateof-the-art dosimetry today includes the use of CT systems for attenuation correction, scatter correction, consideration of the duration of the study depending on the biokinetics of the radiopharmaceutical and of bladder voiding intervals, a calculation of residence times including an analysis of the errors associated with the respective calculation 
method and the appropriate use of phantoms for calculating EDs. As the number of subjects in many biokinetic and dosimetric studies is fewer than 10 the question of the validity of the data for a larger population needs to be addressed. In the scope of the new ICRP recommendations [9] (ICRP 103) gender-specific differences might also need to be considered in the future.

In some cases it was very difficult to find data on biokinetics and dosimetry, especially for radiopharmaceuticals that changed their name during the approval phase. For example, it was not clear at first glance that ${ }^{123} \mathrm{I}-$ Ioflupane and ${ }^{123}$ I-FP-CIT are identical. The same applies to ${ }^{99 \mathrm{~m}} \mathrm{Tc}-\mathrm{HMPAO}$ and ${ }^{99 \mathrm{~m}} \mathrm{Tc}$-exametazime. For some radiopharmaceuticals with marketing authorization such as ${ }^{99 \mathrm{~m}} \mathrm{Tc}$-antigranulocyte no peer-reviewed articles containing dosimetry data have been published; thus the quality of the underlying experimental data cannot be assessed. For ${ }^{18} \mathrm{~F}$-fluoride, a more frequently used PET radiopharmaceutical, no whole-body quantitative imaging data are available, and the biokinetic models rely only on compartment models (based on blood and urinary excretion) and/or local quantitative images. For ${ }^{68}$ Ga-DOTATATE no published data on dosimetry are available.

For some radiopharmaceuticals the biokinetic data were acquired more than 20 years ago (e.g. ${ }^{67} \mathrm{Ga}$-citrate, ${ }^{99 \mathrm{~m}} \mathrm{Tc}$ DMSA, ${ }^{99 \mathrm{~m}}$ Tc-DTPA, ${ }^{99 \mathrm{~m}}$ Tc-ECD, ${ }^{99 \mathrm{~m}} \mathrm{Tc}-\mathrm{MAA},{ }^{99 \mathrm{~m}} \mathrm{Tc}-$ pertechnetate, ${ }^{99 \mathrm{~m}} \mathrm{Tc}$-sestamibi, and ${ }^{18} \mathrm{~F}$-fluoride). Due to considerable improvements in nuclear medicine equipment over the years, an improved assessment of the absorbed doses seems warranted and would be of scientific interest. For ${ }^{201} \mathrm{Tl}$-chloride, a recalculation of the absorbed doses in ICRP 106 [3] following reevaluation of the available data on testicular uptake led to a substantially decreased ED compared to ICRP 80 [2] (11 $\mathrm{mSv}$ vs. $17 \mathrm{mSv}$ with an administered activity of $75 \mathrm{MBq}$ ).

Dosimetry data for paediatric nuclear medicine applications of radiopharmaceuticals are sparse. In the case of missing paediatric data, the ICRP reports use the biokinetics obtained in adults and paediatric age-dependent mathematical phantoms. As the size and weight of children and adolescents vary considerably and show only a poor correlation with age, the dose coefficients (listed in the ICRP publications) should be adjusted according to weight instead.

The latest publication of the ICRP on absorbed doses for radiopharmaceuticals (ICRP 106) [3] still applies the tissue weighting factors given in ICRP 60 [10]. The 2007 ICRP recommendations (ICRP 103) [9] now clearly demand the use of male and female reference voxel phantoms which were published in ICRP 110 [111]. The new concept demands a determination of the equivalent doses to the organs and tissues of the reference male and the reference female separately. In order to obtain the equivalent doses to the reference person, the gender-specific equivalent doses are averaged; hence the new tissue weighting factors can be applied. Moreover, according to ICRP 103, only the latest ICRP voxel phantoms should be used for the calculations of ED. Applying the new weighting factors to a set of equivalent organ doses previously calculated with a mathematical phantom will therefore not result in a correct ED value due to ICRP 103. Presently, the modified tissue weighting factors and the subsequent calculation of the ED according to the formalism of ICRP 103 cannot be applied to nuclear medicine as the S-values for radiopharmaceuticals using the new recommendations of the ICRP are still missing.

As, in many cases, the dosimetry protocols applied for a given radiopharmaceutical are very heterogeneous with respect to the time-points and bladder voiding, and to the dose assessment after the last data point (e.g. for ${ }^{18} \mathrm{~F}$ choline, ${ }^{18} \mathrm{~F}-\mathrm{FDG},{ }^{99 \mathrm{~m}} \mathrm{Tc}-\mathrm{ECD}$ and $\left.{ }^{99 \mathrm{~m}} \mathrm{Tc}-\mathrm{HMPAO}\right)$. Therefore, the development of more uniform protocol templates for diagnostic nuclear medicine dosimetry is required.

In many articles the description of the methodology and the reporting of the results are incomplete so that it is difficult to get information for reassessment of absorbed doses. In future articles the use of the suggestions given by the EANM guidance document on good dosimetry reporting [4] is strongly recommended.

\section{Conclusion}

For most diagnostic radiopharmaceuticals dosimetry data are available, although the data collection and calculation methods are heterogeneous. As some of the data were acquired more than 20 years ago, it would be of interest to generate new data on biokinetics and dosimetry in diagnostic nuclear medicine using state-of-the art equipment and more uniform dosimetry protocols. Data for paediatric nuclear medicine are missing in most cases.

As some of the references collected for this review are not easily accessible a major conclusions of this work is that, for easier public access to dosimetry data of diagnostic radiopharmaceuticals, a database containing these data should be created and maintained.

Acknowledgment This work was conducted within the project PEDDOSE.NET (www.peddose.net) which is financially supported by the European Commission under the 7th Framework Programme FP7-Health-2009-1.2-6 (grant agreement number 241608).

This work is fully endorsed by the Dosimetry Committee of the EANM.

\section{Conflicts of interest None.}

Open Access This article is distributed under the terms of the Creative Commons Attribution Noncommercial License which permits any noncommercial use, distribution, and reproduction in any medium, provided the original author(s) and source are credited. 


\section{References}

1. ICRP. Publication 53: Radiation dose to patients from radiopharmaceuticals. Ann ICRP. 1987;18(1-4).

2. ICRP. Publication 80: Radiation dose to patients from radiopharmaceuticals: Addendum 2 to ICRP publication 53. Ann ICRP. 1998;28 (3).

3. ICRP. Publication 106: Radiation dose to patients from radiopharmaceuticals: Addendum 3 to ICRP Publication 53. Ann ICRP. 2008;38 (1-2).

4. Lassmann M, Chiesa C, Flux G, Bardiès M. EANM Dosimetry Committee guidance document: good practice of clinical dosimetry reporting. Eur J Nucl Med Mol Imaging. 2011;38(1):192-200.

5. Bolch WE, Eckerman KF, Sgouros G, Thomas SR. MIRD Pamphlet No. 21: A generalized schema for radiopharmaceutical dosimetry - standardization of nomenclature. J Nucl Med. 2009;50(3):477-84.

6. Fisher DR, Shen S, Meredith RF. MIRD Dose Estimate Report No. 20: Radiation absorbed-dose estimates for ${ }^{111} \mathrm{In}$ - and ${ }^{90} \mathrm{Y}$ ibritumomab tiuxetan. J Nucl Med. 2009;50(4):644-52.

7. Siegel JA, Thomas SR, Stubbs JB, Stabin MG, Hays MT, Koral KF, et al. MIRD Pamphlet No. 16: Techniques for quantitative radiopharmaceutical biodistribution data acquisition and analysis for use in human radiation dose estimates. J Nucl Med. 1999;40 (2):37S-61S

8. Snyder WS, Ford MR, Warner GG, Watson SB. MIRD Pamphlet No 11: S, absorbed dose per unit cumulated activity for selected radionuclides and organs. Reston: Society of Nuclear Medicine; 1975.

9. ICRP. Publication 103: The 2007 recommendations of the International Commission of Radiological Protection. Ann ICRP. 2007:37 (2-4).

10. ICRP. Publication 60: 1990 recommendations of the International Commission on Radiological Protection. Ann ICRP. 1991;21 (1-3).

11. ICRP. Publication 26: Recommendations of the ICRP. Ann ICRP. 1971;1(3).

12. Stabin MG. Uncertainties in internal dose calculations for radiopharmaceuticals. J Nucl Med. 2008;49(5):853-60.

13. van den Hoff J, Burchert W, Wolpers HG, Meyer GJ, Hundeshagen $\mathrm{H}$. A kinetic model for cardiac PET with [1-carbon-11]acetate. J Nucl Med. 1996;37(3):521-9.

14. Bouchelouche K, Turkbey B, Choyke P, Capala J. Imaging prostate cancer: an update on positron emission tomography and magnetic resonance imaging. Curr Urol Rep. 2010;11 (3):180-90.

15. Seltzer MA, Jahan SA, Sparks R, Stout DB, Satyamurthy N, Dahlbom M, et al. Radiation dose estimates in humans for (11)Cacetate whole-body PET. J Nucl Med. 2004;45(7):1233-6.

16. Stabin MG. MIRDOSE: Personal computer software for internal dose assessment in nuclear medicine. J Nucl Med. 1996;37 (3):538-46.

17. Shields AF, Graham MM, Kozawa SM, Kozell LB, Link JM, Swenson ER, et al. Contribution of labeled carbon dioxide to PET imaging of carbon-11-labeled compounds. J Nucl Med. 1992;33(4):581-4.

18. Leggett RW, Williams LR. A proposed blood circulation model for Reference Man. Health Phys. 1995;69(2):187-201.

19. Roivainen A, Forsback S, Grönroos T, Lehikoinen P, Kähkönen $\mathrm{M}$, Sutinen E, et al. Blood metabolism of [methyl-11C]choline; implications for in vivo imaging with positron emission tomography. Eur J Nucl Med. 2000;27(1):25-32.

20. Tolvanen T, Yli-Kerttula T, Ujula T, Autio A, Lehikoinen P, Minn $\mathrm{H}$, et al. Biodistribution and radiation dosimetry of $\left[{ }^{11} \mathrm{C}\right]$ choline: a comparison between rat and human data. Eur J Nucl Med Mol Imaging. 2010;37(5):874-83.
21. Deloar HM, Fujiwara T, Nakamura T, Itoh M, Imai D, Miyake $\mathrm{M}$, et al. Estimation of internal absorbed dose of L-[methyl-11C] methionine using whole-body positron emission tomography. Eur J Nucl Med. 1998;25(6):629-33.

22. O'Keefe GJ, Saunder TH, Ng S, Ackerman U, TochonDanguy HJ, Chan JG, et al. Radiation dosimetry of betaamyloid tracers ${ }^{11} \mathrm{C}-\mathrm{PiB}$ and 18F-BAY94-9172. J Nucl Med. 2009;50(2):309-15.

23. IASON. IASOcholine: [18F] fluorocholine. http://www.iason.eu/ en/products/iasocholine.html. Accessed 10 Aug 2011.

24. DeGrado TR, Reiman RE, Price DT, Wang S, Coleman RE. Pharmacokinetics and radiation dosimetry of $18 \mathrm{~F}$-fluorocholine. J Nucl Med. 2002;43(1):92-6. Erratum in: J Nucl Med 2002 Apr;43(4):509

25. Nosske D, Brix G. Dose assessment for C-11- and F-18-choline. J Nucl Med. 2009;50 Suppl 2:1851.

26. Janzen T, Tavola F, Giussani A, Cantone MC, Uusijarvi H, Mattsson S, et al. Compartmental model of ${ }^{18} \mathrm{~F}$-choline. Proc SPIE. 2010;7626:76261E. doi:10.1117/12.844219

27. Zankl M, Petoussi-Henss N, Janzen T, Uusijärvi H, Schlattl H, Li $\mathrm{WB}$, et al. New calculations for internal dosimetry of betaemitting radiopharmaceuticals. Radiat Prot Dosimetry. 2010;139 (1-3):245-9.

28. IASON. SPC IASOdopa: Summary of product characteristics. http:// afssaps-prd.afssaps.fr/html/par_eu/20080604_fr328_iasodopa_spc. pdf. Accessed 10 Aug 2011.

29. ICRP. Addendum 4 to ICRP Publication 53 (interim 2002-1015): Radiation dose to patients from radiopharmaceuticals. http:// www.icrp.org/docs/P053_addendum_4_\%28interim_2002-1015\%29.pdf. Accessed 11 Aug 2010.

30. Brown WD, Oakes TR, DeJesus OT, Taylor MD, Roberts AD, Nickles RJ, et al. Fluorine-18-fluoro-L-DOPA dosimetry with carbidopa pretreatment. J Nucl Med. 1998;39 (11):1884-91.

31. Mejia AA, Nakamura T, Masatoshi I, Hatazawa J, Masaki M, Watanuki S. Estimation of absorbed doses in humans due to intravenous administration of fluorine- ${ }^{18}$-fluorodeoxyglucose in PET studies. J Nucl Med. 1991;32(4):699-706.

32. Dowd MT, Chen CT, Wendel MJ, Faulhaber PJ, Cooper MD. Radiation dose to the bladder wall from 2-[ $\left.{ }^{18} \mathrm{~F}\right]$ fluoro-2-deoxyD-glucose in adult humans. J Nucl Med. 1991;32(4):707-12.

33. Hays MT, Segall GM. A mathematical model for the distribution of fluorodeoxyglucose in humans. J Nucl Med. 1999;40 (8):1358-66.

34. Niven E, Thompson M, Nahmias C. Absorbed dose to the adult male and female brain from ${ }^{18} \mathrm{~F}$-fluorodeoxyglucose. Health Phys. 2001;80(1):62-6.

35. Hays MT, Watson EE, Thomas SR, Stabin M. MIRD Dose Estimate Report No. 19: Radiation absorbed dose estimates from ${ }^{18}$ F-FDG. J Nucl Med. 2002;43(2):210-4.

36. Wu TH, Liu RS, Dong SL, Chung YW, Chou KL, Lee JS. Dynamic evaluation of absorbed dose to the bladder wall with a balloonbladder phantom during a study using $\left[{ }^{18} \mathrm{~F}\right]$ fluorodeoxyglucose positron emission imaging. Nucl Med Commun. 2002;23(8):74955 .

37. Deloar HM, Fujiwara T, Shidahara M, Nakamura T, Watabe H, Narita Y, et al. Estimation of absorbed dose for 2-[F-18]fluoro-2deoxy-D-glucose using whole-body positron emission tomography and magnetic resonance imaging. Eur J Nucl Med. 1998;25 (6):565-74.

38. Deloar HM, Fujiwara T, Shidahara M, Nakamura T, Yamadera $\mathrm{A}$, Itoh $\mathrm{M}$. Internal absorbed dose estimation by a TLD method for ${ }^{18} \mathrm{~F}$-FDG and comparison with the dose estimates from whole body PET. Phys Med Biol. 1999;44(2):595-606.

39. Koukouraki S, Strauss LG, Georgoulias V, Eisenhut M, Haberkorn U, Dimitrakopoulou-Strauss A. Comparison of 
the pharmacokinetics of ${ }^{68} \mathrm{Ga}$-DOTATOC and $\left[{ }^{18} \mathrm{~F}\right] \mathrm{FDG}$ in patients with metastatic neuroendocrine tumours scheduled for ${ }^{90}$ Y-DOTATOC therapy. Eur J Nucl Med Mol Imaging. 2006;33 (10):1115-22.

40. Khamwan K, Krisanachinda A, Pasawang P. The determination of patient dose from ${ }^{18} \mathrm{~F}-\mathrm{FDG}$ PET/CT examination. Radiat Prot Dosimetry. 2010;141(1):50-5.

41. Pauleit D, Floeth F, Herzog H, Hamacher K, Tellmann L, Müller $\mathrm{H}-\mathrm{W}$, et al. Whole-body distribution and dosimetry of O- $(2-[18 \mathrm{~F}]$ fluoroethyl)-L-tyrosine. Eur J Nucl Med Mol Imaging. 2003;30 (4):519-24.

42. Charkes ND, Makler PT, Philips C. Studies of skeletal tracer kinetics. I. Digital-computer solution of a five-compartment model of $\left[{ }^{18}\right.$ F $]$ fluoride kinetics in humans. J Nucl Med. 1978;19 (12):1301-9.

43. Hawkins RA, Choi Y, Huang S-C, Hoh CK, Dahlbom M, Schiepers C, et al. Evaluation of the skeletal kinetics of fluorine-18-fluoride ion with PET. J Nucl Med. 1992;33 (5):633-42.

44. Blake GM, Park-Holohan SJ, Cook GJ, Fogelman I. Quantitative studies of bone with the use of ${ }^{18} \mathrm{~F}$-fluoride and ${ }^{99 \mathrm{~m}} \mathrm{Tc}$-methylene diphosphonate. Semin Nucl Med. 2001;31(1):28-49.

45. Drugs.com. Sodium fluoride F-18 injection. http://www.drugs.com/ pro/sodium-fluoride-f-18-injection.html. Accessed 10 Aug 2011.

46. IASON. IASOflu: neue Zulassungen in europäischen Ländern Update. http://www.iason.eu/news/aktuelles/details/article/iasofluneue-zulassungen-in-europaeischen-laendern.html. Accessed 10 Aug 2011.

47. IASON. IASOflu: [18F]Natriumfluorid. http://www.iason.eu/en/ products/iasoflu.html. Accessed 10 Aug 2011.

48. Graham MM, Peterson LM, Link JM, Evans ML, Rasey JS, Koh WJ, et al. Fluorine-18-fluoromisonidazole radiation dosimetry in imaging studies. J Nucl Med. 1997;38(10):1631-6.

49. Pettinato C, Sarnelli A, Di Donna M, Civollani S, Nanni C, Montini G, et al. ${ }^{68} \mathrm{Ga}$-DOTANOC: biodistribution and dosimetry in patients affected by neuroendocrine tumors. Eur J Nucl Med Mol Imaging. 2008;35(1):72-9.

50. Garkavij M, Nickel M, Sjögreen-Gleisner K, Ljungberg $M$, Ohlsson T, Wingårdh $\mathrm{K}$, et al. ${ }^{177} \mathrm{Lu}$-[DOTA0,Tyr3] octreotate therapy in patients with disseminated neuroendocrine tumors: analysis of dosimetry with impact on future therapeutic strategy. Cancer. 2010;116(4 Suppl):1084-92.

51. Hartmann H, Zöphel K, Freudenberg R, Oehme L, Andreeff M, Wunderlich $\mathrm{G}$, et al. Radiation exposure of patients during ${ }^{68} \mathrm{Ga}$ DOTATOC PET/CT examinations. Nuklearmedizin. 2009;48 (5):201-7.

52. Drugs.com. Cardiogen-82. http://www.drugs.com/pro/cardiogen82.html. Accessed 10 Aug 2011.

53. Kearfott KJ. Radiation absorbed dose estimates for positron emission tomography (PET): K-38, Rb-81, Rb-82, and Cs-130. J Nucl Med. 1982;23(12):1128-32.

54. Ryan J, Harper P, Stark V, Peterson E, Lathrop K. Radiation absorbed dose estimate for Rb-82 using in vivo measurements in man (abstract). J Nucl Med. 1984;25(5):94P.

55. Stabin MG. Proposed revision to the radiation dosimetry of ${ }^{82} \mathrm{Rb}$. Health Phys. 2010;99(6):811-3.

56. Stabin MG, Sparks RB, Crowe E. OLINDA/EXM: the second-generation personal computer software for internal dose assessment in nuclear medicine. J Nucl Med. 2005;46 (6): 1023-7.

57. Senthamizhchelvan S, Bravo PE, Esaias C, Lodge MA, Merrill J, Hobbs RF, et al. Human biodistribution and radiation dosimetry of ${ }^{82} \mathrm{Rb}$. J Nucl Med. 2010;51(10):1592-9.

58. Senthamizhchelvan S, Bravo PE, Lodge MA, Merrill J, Bengel FM, Sgouros G. Radiation dosimetry of ${ }^{82} \mathrm{Rb}$ in humans under pharmacologic stress. J Nucl Med. 2011;52(3):485-91.
59. European Medicines Agency. Scintimun: besilesomab. http://www. ema.europa.eu/ema/index.jsp?curl=pages/medicines/human/medi cines/001045/human_med_001232.jsp\&murl=menus/medicines medicines.jsp\&mid=WC0b01ac058001d124. Accessed 11 Aug 2011.

60. Becker W, Borst U, Fischbach W, Pasurka B, Schäfer R, Börner W. Kinetic data of in-vivo labeled granulocytes in humans with a murine Tc-99m-labelled monoclonal antibody. Eur J Nucl Med. 1989;15(7):361-6.

61. Becker W, Goldenberg DM, Wolf F. The use of monoclonal antibodies and antibody fragments in the imaging of infectious lesions. Semin Nucl Med. 1994;24(2):142-53.

62. Buchmann I, Kull T, Glatting G, Bunjes D, Hale G, Kotzerke J, et al. A comparison of the biodistribution and biokinetics of $(99 \mathrm{~m}) \mathrm{Tc}-$ anti-CD66 mAb BW 250/183 and ${ }^{99 \mathrm{~m}}$ Tc-anti-CD45 mAb YTH 24.5 with regard to suitability for myeloablative radioimmunotherapy. Eur J Nucl Med Mol Imaging. 2003;30(5):667-73.

63. IBA Molecular. Scintimun Granulocyte (in German). 2009

64. Malone LA, Malone JF, Ennis JT. Kinetics of technetium 99m labelled macroaggregated albumin in humans. $\mathrm{Br} \mathrm{J}$ Radiol. 1983;56(662):109-12.

65. MIRD. MIRD Dose Estimate Report No. 8. Summary of current radiation dose estimates to normal humans from ${ }^{99 \mathrm{~m}} \mathrm{Tc}$ as sodium pertechnetate. J Nucl Med. 1976;17(1):74-7.

66. Hays MT, Berman M. Pertechnetate distribution in man after intravenous infusion: a compartmental model. J Nucl Med. 1977;18(9):898-904.

67. Smith T, Petoussi-Henss N, Zankl M. Comparison of internal radiation doses estimated by MIRD and voxel techniques for a "family" of phantoms. Eur J Nucl Med Mol Imaging. 2000;27 (9):1387-98.

68. Wackers FJ, Berman DS, Maddahi J, Watson DD, Beller GA, Strauss HW, et al. Technetium-99m hexakis 2-methoxyisobutyl isonitrile: human biodistribution, dosimetry, safety, and preliminary comparison to thallium-201 for myocardial perfusion imaging. J Nucl Med. 1989;30(3):301-11.

69. Leide S, Diemer H, Ahlgren L. In vivo distribution and dosimetry of Tc-99m MIBI in man. In: Watson E, Stelson A, editors. Fifth International Radiopharmaceutical Dosimetry Symposium. CONF-910529. Oak Ridge, TN: Oak Ridge Associated Universities; 1992. p. 483-97.

70. Cyclopharm. Technegas. http://www.cyclopharm.com/de/technegas4. Accessed 10 Aug 2011.

71. Burch WM, Sullivan PJ, McLaren CJ. Technegas - a new ventilation agent for lung scanning. Nucl Med Commun. 1986;7 (12):865-71.

72. Kereiakles JG, Rosenstein M. Handbook of radiation doses in nuclear medicine and diagnostic X-ray. Florida: CRC Press; 1980.

73. Snyder WS, Ford MR, Warner GG. MIRD Pamphlet No 5 revised: Estimates of absorbed fractions for monoenergetic photon sources uniformly distributed in various organs of a heterogeneous phantoms. Reston: Society of Nuclear Medicine; 1978.

74. ICRP. Publication 23: Reference Man: Anatomical, physiological and metabolic characteristics. Oxford: Pergamon Press; 1975.

75. Cristy M. Mathematical phantoms representing children of various ages for use in estimates of internal dose. Report ORNL/NUREG/TM-367. US Nuclear Regulatory Commission and Oak Ridge National Laboratory; 1980.

76. Cristy M, Eckerman KF. Specific absorbed fractions of energy at various ages from internal photon sources. ORNL/TM-8381 V1V7. Oak Ridge National Laboratory; 1987.

77. Stabin MG, Siegel JA. Physical models and dose factors for use in internal dose assessment. Health Phys. 2003;85 (3):294-310. 
78. Smith T, Lahiri A, Gemmell HG, Davidson J, Smith FW, Pickett $\mathrm{RD}$, et al. Dosiemtry of ${ }^{99 \mathrm{~m}} \mathrm{Tc}-\mathrm{P} 53$, a new myocardial perfusion imaging agent. In: Fifth International Radiopharmaceutical Dosimetry Symposium. CONF-910529, Oak Ridge Associated Universities, Oak Ridge, TN,. 1992. p. 467-481.

79. Higley B, Smith FW, Smith T, Gemmell HG, Das Gupta P, Gvozdanovic DV, et al. Technetium-99m-1,2-bis[bis(2-ethoxyethyl) phosphino]ethane: human biodistribution, dosimetry and safety of a new myocardial perfusion imaging agent. J Nucl Med. 1993;34 (1):30-8.

80. GE Healthcare. Myoview. http://md.gehealthcare.com/shared/ pdfs/pi/Myoview.pdf. Accessed 10 Aug 2011.

81. Thomas SR, Stabin MG, Castronovo FP. Radiation-absorbed dose from ${ }^{201}$ Tl-thallous chloride. J Nucl Med. 2005;46(3):5028 .

82. Krahwinkel W, Herzog H, Feinendegen LE. Pharmacokinetics of thallium-201 in normal individuals after routine myocardial scintigraphy. J Nucl Med. 1988;29(9):1582-6.

83. Johansson L, Leide-Svegborn S, Mattsson S, Nosslin B. Biokinetics of iodide in man: refinement of current ICRP dosimetry models. Cancer Biother Radiopharm. 2003;18 (3):445-50.

84. Booij J, Busemann Sokole E, Stabin MG, Janssen AG, de Bruin $\mathrm{K}$, van Royen EA. Human biodistribution and dosimetry of $\left[{ }^{123} \mathrm{I}\right]$ FP-CIT: a potent radioligand for imaging of dopamine transporters. Eur J Nucl Med. 1998;25(1):24-30. Erratum in: Eur J Nucl Med 1998;25(4):458

85. GE Healthcare. DaTSCAN: EPAR-Product Information. 2007; http://www.ema.europa.eu. Accessed 14 Oct 2010.

86. Virgolini I, Szilvasi I, Kurtaran A, Angelberger P, Raderer M, Havlik E, et al. Indium-111-DOTA-lanreotide: biodistribution, safety and radiation absorbed dose in tumor patients. J Nucl Med. 1998;39(11):1928-36.

87. Rodrigues $\mathrm{M}$, Traub-Weidinger $\mathrm{T}$, Li S, Ibi B, Virgolini I. Comparison of ${ }^{111}$ In-DOTA-DPhe1-Tyr3-octreotide and ${ }^{111}$ InDOTA-lanreotide scintigraphy and dosimetry in patients with neuroendocrine tumours. Eur J Nucl Med Mol Imaging. 2006;33 (5):532-40.

88. Forrer $\mathrm{F}$, Uusijärvi $\mathrm{H}$, Waldherr $\mathrm{C}$, Cremonesi $\mathrm{M}$, Bernhardt $\mathrm{P}$, Mueller-Brand J, et al. A comparison of ${ }^{111} \mathrm{In}$-DOTATOC and ${ }^{111}$ In-DOTATATE: biodistribution and dosimetry in the same patients with metastatic neuroendocrine tumours. Eur J Nucl Med Mol Imaging. 2004;31(9):1257-62.

89. Kwekkeboom DJ, Kooij PP, Bakker WH, Mäcke HR, Krenning EP. Comparison of ${ }^{111}$ In-DOTA-Tyr3-octreotide and $111 \mathrm{In}$-DTPA-octreotide in the same patients: biodistribution, kinetics, organ and tumor uptake. J Nucl Med. 1999;40 (5):762-7.

90. Cremonesi M, Ferrari M, Zoboli S, Chinol M, Stabin MG, Orsi $\mathrm{F}$, et al. Biokinetics and dosimetry in patients administered with ${ }^{111}$ In-DOTA-Tyr3-octreotide: implications for internal radiotherapy with 90Y-DOTATOC. Eur J Nucl Med Mol Imaging. 1999;26 (8):877-86.

91. Bajc M, Palmer J, Ohlsson T, Edenbrandt L. Distribution and dosimetry of ${ }^{111}$ In DTPA-D-Phe-octreotide in man assessed by whole body scintigraphy. Acta Radiol. 1994;35(1):53-7.

92. Stabin MG, Kooij PP, Bakker WH, Inoue T, Endo K, Coveney J, et al. Radiation dosimetry for indium-111-pentetreotide. J Nucl Med. 1997;38(12):1919-22.

93. Förster GJ, Engelbach MJ, Brockmann JJ, Reber HJ, Buchholz HG, Mäcke HR, et al. Preliminary data on biodistribution and dosimetry for therapy planning of somatostatin receptor positive tumours: comparison of ${ }^{86}$ Y-DOTATOC and ${ }^{111}$ In-DTPA-octreotide. Eur J Nucl Med. 2001;28(12):1743-50.
94. Helisch A, Förster GJ, Reber H, Buchholz H-G, Arnold R, Göke $\mathrm{B}$, et al. Pre-therapeutic dosimetry and biodistribution of ${ }^{86} \mathrm{Y}-$ DOTA-Phe1-Tyr3-octreotide versus 111In-pentetreotide in patients with advanced neuroendocrine tumours. Eur $\mathrm{J}$ Nucl Med Mol Imaging. 2004;31(10):1386-92.

95. Wiseman GA, White CA, Stabin M, Dunn WL, Erwin W, Dahlbom M, et al. Phase I/II ${ }^{90}$ Y-Zevalin (yttrium-90 ibritumomab tiuxetan, IDEC-Y2B8) radioimmunotherapy dosimetry results in relapsed or refractory non-Hodgkin's lymphoma. Eur J Nucl Med. 2000;27(7):766-77.

96. Wiseman GA, White CA, Sparks RB, Erwin WD, Podoloff DA, Lamonica $\mathrm{D}$, et al. Biodistribution and dosimetry results from a phase III prospectively randomized controlled trial of Zevalin radioimmunotherapy for low-grade, follicular, or transformed B-cell non-Hodgkin's lymphoma. Crit Rev Oncol Hematol. 2001;39(1-2):181-94.

97. MIRD. Dose Estimate Report No. 2. Summary of current radiation dose estimates to humans from ${ }^{66} \mathrm{Ga}-,{ }^{67} \mathrm{Ga},{ }^{68} \mathrm{Ga}-$, and ${ }^{72}$ Ga-citrate. J Nucl Med. 1973;14(10):755-756.

98. Ruotsalainen U, Suhonen-Polvi H, Eronen E, Kinnala A, Bergman J, Haaparanta M, et al. Estimated radiation dose to the newborn in FDG-PET studies. J Nucl Med. 1996;37(2):387-93.

99. Cristy M, Eckerman KF. Specific absorbed fractions of energy at various ages from internal photon sources. I. Methods. ORNL/ TM-8381/V1. Oak Ridge National Laboratory; 1987.

100. Niven E, Nahmias C. Absorbed dose to very low birth weight infants from ${ }^{18}$ F-fluorodeoxyglucose. Health Phys. 2003;84 (3):307-16.

101. Gelfand MJ. Dosimetry of FDG PET/CT and other molecular imaging applications in pediatric patients. Pediatr Radiol. 2009;39 Suppl 1:46-56.

102. Lim R, Fahey FH, Drubach LA, Connolly LP, Treves ST. Early experience with fluorine-18 sodium fluoride bone PET in young patients with back pain. J Pediatr Orthop. 2007;27(3):277-82.

103. Fahey FH. Dosimetry of pediatric PET/CT. J Nucl Med. 2009;50 (9):1483-91.

104. Piepsz A, Hahn K, Roca I, Ciofetta G, Toth G, Gordon I, et al. A radiopharmaceuticals schedule for imaging in paediatrics. Paediatric Task Group European Association Nuclear Medicine. Eur J Nucl Med. 1990;17(3-4):127-9.

105. Evans K, Lythgoe MF, Anderson PJ, Smith T, Gordon I. Biokinetic behavior of technetium-99m-DMSA in children. $\mathrm{J}$ Nucl Med. 1996;37(8):1331-5.

106. Smith T, Evans K, Lythgoe MF, Anderson PJ, Gordon I. Radiation dosimetry of technetium-99m-DMSA in children. $\mathrm{J}$ Nucl Med. 1996;37(8):1336-42.

107. Vestergren E, Jacobson L, Mattson S, Johansson L, Bjure J, Sixt $\mathrm{R}$, et al. Biokinetics and dosimetry of Tc-99m HM-PAO in children. In: Stelson A, Watson E, editors. Fifth International Radiopharmaceutical Dosimetry Symposium. CONF-910529. Oak Ridge: Oak Ridge Associated Universities; 1992. p. 444-56.

108. Stabin M, Taylor A, Conway J, Eshima D, Wooten W, Halama J. Radiation dosimetry for Tc-99m MAG 3 in adults and children. In: Stelson A, Watson E, editors. Fifth International Radiopharmaceutical Dosimetry Symposium. CONF-910529. Oak Ridge: Oak Ridge Associated Universities; 1992. p. 432-43.

109. Gelfand MJ, Thomas SR, Kereiakes JG. Absorbed radiation dose from routine imaging of the skeleton in children. Ann Radiol (Paris). 1983;26(5):421-3.

110. ICRU. Absorbed-dose specification in nuclear medicine (report 67). J ICRU. 2002;2(1).

111. ICRP. Publication 110: Adult reference computational phantoms. Ann ICRP. 2009;30(2). 